\title{
CONTEMPORARY CONSUMER IN THE GLOBAL ENVIRONMENT
}

\author{
Aleksandar Grubor ${ }^{1}$, Dražen Marić ${ }^{2}$
}

Abstract: One of the characteristics of human society in the $21^{\text {st }}$ century is that the individual is increasingly viewed predominantly as a consumer. The turbulent development of science and technology has also resulted in new, changed consumer behavior patterns, which are achieving a new role in the modern society. Research into consumer behavior imposes itself as an imperative of successful functioning of the economic and social system.

Problem statement: Many companies are faced with serious problems of effectiveness and efficiency of their conducted marketing activities. The consumer is predominantly becoming the central factor determining a company's corporate performance, but the key problem lies in the fact that the prevalent philosophy of the marketing practices still regards the consumers as "passive end users" of the value created, neglecting their changed role, behavior, and impact on market processes.

Approach: Presenting and analyzing the results of research from marketing literature dealing with the problem of changed market behavior, this article aims to point to the necessity to change the thinking patterns of marketing theory and practice on the significance and impact of the consumer on companies' corporate performance by accepting new roles that the consumers have in the contemporary society.

Results: By changing the attitude toward consumers as key stakeholders on the market and accepting their new roles, companies get guidelines for shaping and amending their marketing strategies toward raising the quality of corporate performance, and the same stands for institutions responsible for the functioning of a society and the state as a whole.

Conclusion: The current marketing reality inexorably promotes the notion that consumer behavior as a whole is an essential social process shaped by intensive word-of-mouth communication. As a science and practice, marketing must become a complex and fluid system of network relationships, constantly redefining itself toward integration with the changes of contemporary consumers and their modus vivendi.

JEL Classification Numbers: M3, DOI: http://dx.doi.org/10.12955/cbup.v3.580

Keywords: consumer, behavior, marketing, word of mouth, consumerism, globalization

\section{Introduction}

The contemporary human society and development of the modern civilization are characterized by high dynamism, which can be viewed, as it were, through two epoch-making changes: a turbulent development of science and technology, and fundamental cultural changes (Firat \& Dholakia, 2006, p. 123). These cultural changes are what academic and professional literature terms evolution of modernism into post-modernism. The dynamic and continuous development of technology, on the other hand, results in completely new products and services, work and business systems, lifestyles and inter-personal communication, and not only powerfully generates and influences cultural changes, but is at the same time subject to their influence.

The essence of contemporary marketing could be viewed in terms of observing, analyzing, building, preserving, and advancing relationships of both organizations and individuals with their stakeholders. Marketing is, nowadays, taken as the basic creed and a way of overall existence, not only in the sphere of economy and business, but also as a very popular impetus of the modern culture in general. "Know and serve YOUR customer" is becoming a generally accepted principle of business and existence (Urban, 2005).

\section{The modern consumer as an active participant of market exchange}

Marketing, nowadays, completely shapes national and global policies, creates and influences the way individuals create and maintains their personal relationships with others-families, friends, employers

\footnotetext{
${ }^{1}$ Aleksandar Grubor, PhD, Professor, University of Novi Sad, Faculty of Economics in Subotica, Serbia, agrubor@ef.uns.ac.rs

${ }^{2}$ Dražen Marić, PhD, Assistant Lecturer, University of Novi Sad, Faculty of Economics in Subotica, Serbia, drdrazen75@yahoo.com
} 
and co-workers. And what is important to point out is the way individuals perceive themselves (Andrusia \& Haskins, 2000).

Postmodern marketing features as a cultural foundation stone of the contemporary social existence. As such, it permeates all the pores of existence of individuals and organizations, and has arisen as the basic principle of building and functioning of all types of relationships in society, both business and personal ones. Such success is the consequence of the fact that marketing contains the essence of modern culture and democracy (Firat \& Dholakia, 2006, p. 124). Within such a complex economic and social setting, an individual begins to be predominantly viewed as a consumer, and this social role becomes dominant in relation to all other social an individual has- the roles of friend, citizen, teacher, manager, etc.

All the rights and powers that an individual claims or holds in society are derived from their position as a consumer. Political choices and decisions are made based on individuals' assessments as to what will benefit them most as consumers. An individual's quality and enjoyment of life is, nowadays, predominantly determined by means of quantity and quality of what they can afford and spend. Even the individual's social success is measured through the consumer prism of materialism. Spending today does not only have the sense of meeting the needs of individuals and institutions, but also represents the perimeter of social relations, personal and group identity, image, and perception.

On the one hand, the contemporary social ambience places the consumer on the pedestal of deity, to whom the entire set of policies and economy is subservient. The consumer is the absolute ruler dictating the technological progress, innovation, process of creating new values, political changes and events, and it is only the consumer that has the power to save nature and the future of the human civilization. On the other hand, the consumer is also presented as a passive, immature, naive, suggestive, dependent and weak entity, easy to manipulate. A consumer is somebody who, due to their dependence and eternal search for growth in their living standards and their unrealistic dreams and illusions, is rather a mere pawn in the game of power-wielders and shadow rulers.

The consumer is today, undoubtedly, the central point in academic circles and debates. If the approach of the traditional sociological theories and political economics of the $19^{\text {th }}$ century can be said to view individuals as laborers and creators of value and wealth, the $21^{\text {st }}$ century theories can be said to focus primarily on consumption and consumers. Thus, modern-day psychology devotes increasing attention to studying behavioral motives of individuals as consumers. Whether we refer to stages of social development as late modernism, post-modernism, or advanced capitalism, sociologists and modern culture theoreticians no longer see the key factors of the degree of social development in approaches to production or governance of the state and society, but rather in manners of consumption. The collapse of communism in the Eastern bloc also contributed to the establishment of consumerism as an indisputable ideology of modern-day human civilization. Many experts in the field of social sciences and humanities believe that consumerism, rather than democracy or capitalism, is the winner of the ideological battle of the $20^{\text {th }}$ century and, as such, represents the fundamental characteristic of the modern human society and nations (Flavin, 2004, p. xvii).

Consumerism can be defined as a social movement designed to increase and strengthen the rights and power of consumers and buyers in relation to producers and sellers (Kotler \& Keller, 2006, p. 95). Consumerism has proved useful both for the individual consumers and for the entirety of an economy and state. The growing interest in the questions and applications of marketing ethics in practice results from the development of consumerism in the world. Marketing ethics deal with the moral criticism of companies' and individuals' business behavior. In market economies, companies' behavior is closely connected with consumer behavior, so that many social critics believe that every business has the consumers it deserves, and vice versa (Brinkmann \& Peattie, 2008, p. 22). 
Any discussion related to consumers and consumption is rarely neutral in terms of value and ideology. Some authors view and extol the rise of consumers and consumerism in general, from the standpoint that religion and politics cannot bring the necessary improvement and salvation to society. They understand the consumer as a mature entity that seeks to achieve contentment with life by means of choice and will. Other authors, however, protest discontentedly and express their regret because of it all, as they view consumerism as the final stage of use and exploitation. Culturologists view the consumer as the unit that is the most selfish and most dangerous to the environment.

The concept of consumers and their role in society and economy is so complex that it also includes different sociological and culturological dimensions. In turn, it is dealt with by economists, marketers, and also sociologists, culturologists, Marxists, journalists, publishers, politicians, environmentalists and many others, wherein any one of them may, and usually, have their own understanding of the consumers. A consumer may mean everything to everyone.

Kovač-Žnideršić \& Marić (2007, p. 203) argued that the modern world of consumers and consumption is shaped through the action of two basic factors: globalization and localization.

Globalism is a concept with a multitude of various definitions in the modern literature, with each of them serving its purpose. One of them defines globalization as a process in which consumers, enterprises and companies, as well as national governments, interlink increasingly in various relations surpassing their national boundaries (Arnould, Price, \& Zinkhan, 2004, p. 32). The essence of the globalization process lies in increasing mobility of not only people, capital, goods and services, but also information and knowledge. Globalization creates new social relations and networks, breaking through the national boundaries of sovereign states. The emergence of the Internet has contributed to a fantastic revolution in the sphere of economy and business, and made a highly stimulating impact on the globalization process. All contemporary forms of business transactions, such as business-tobusiness, business-to-consumer, government-to-consumer, and consumer-to-consumer, transcending national boundaries, would be practically unimaginable without the Internet. Globalization is a continuous process, and currently the law of business, where the limiting impact of geographic factors on social and cultural links, relations and actions is marginalized.

Localization may be understood as an effort and endeavor to preserve the sense of identity, personal and national roots, traditions, homes, and communities (Arnould et al., 2004, p. 33). Localization testifies to a powerful rebirth and revival of local cultures as a response to the unstoppable wave of globalization. Everywhere in the world, consumers are increasingly expressing the desire to return to the roots of their cultures, but, at the same time, adapt global products and services, brands and messages, norms and values, so that they can fit into their national and local cultures.

Nowadays, intense intertwining, mutual permeation, and conditioning of the globalization and localization processes represent the contemporary environment in which consumers browse, choose, use, and assess the products and services of various users, i.e. where they form, maintain, and change their opinions, attitudes, and behaviors in general (Kovač-Žnideršić \& Marić, 2007, p. 204).

Kotler \& Keller (2006, p. 78) pointed out that the beginning of the new millennium has brought about a whole range of new challenges - sharp and dramatic decline of stock exchanges, decline in the savings level, decline in the investment levels, loss of pension funds value, increase in unemployment, corporate scandals and fraud, and growth of terrorism worldwide. These dramatic changes and events introduced the global economic crisis, and, parallel with the already existing long-term trend, made a deep impact and shaped the image of the contemporary marketing and social setting where the consumers exist. Within such a global situation, which is changing in character, we must follow six groups of factors-demographic, economic, socio-cultural, political and legal, natural and technological factors, and affecting to consumer behavior. 
The issue of current behavior patterns should be viewed simultaneously, in terms of basic division between developed and developing countries. It is beyond a doubt that the market characteristics, their potential, size, purchasing power, consumer preferences, legal regulations, and many other factors are highly specific when one views the markets of developing countries compared to the markets of developing countries, which all results in specific modalities of consumer behavior on these markets.

Arnould et al. (2004, p. 44) identified the consumer behavior patterns on developed markets through the following trends:

- Consumer education - the essential characteristic of these markets, referring, above all, to the exceptionally high education levels of consumers, and the knowledge they possess about the products and services offered to them, so that in the conditions of higher supply in relation to demand, in the conditions of the fiercest competitive struggle on the market ever, each consumer decision related to a purchase implies a complex process where the consumer is required to have high levels of knowledge and skills. Most consumers on these markets are highly price and value conscious when choosing commodities. Consumers are accustomed to noticing even the slightest differences between very similar products and brands, and are also ready to accept any innovation on the product or method of its use. What is also very interesting is the specific connection, i.e. the relationship that the consumers have with their preferred brands on these markets, but even more important is the relationship between consumers themselves. However, due to excessively aggressive marketing communication from companies to consumers, the latter loses confidence in formal sources of information, educating themselves in relations with other consumers through word of mouth communication. The purchase decision is increasingly under the influence of experience and other consumers rather than companies.

- Recreational shopping - contemporary, modern, personalized shopping, in all its variations, implies an event in which consumers become pilgrims aiming to meet a broad spectrum of needs and desires, including aesthetic pleasure, hedonism, problem resolution, and affirmation of their own personality. To render the experience and purchase satisfaction even greater, many producers strive to combine entertainment and shopping in their offer and the setting where shopping occurs, creating theme department stores, and shopping parks where consumers can either actually or virtually participate in numerous sports, games, or challenges as they pause while shopping.

- Experimental spending - a trend in the most developed countries of the world, which arose as a consequence of a growing significance and participation of consumption in free time and the so-called tourist spending, especially for eco-tourism and adventure holidays. It is also interesting to mention a specific form of tourist services and consumption, which records exponential growth - organized gambling in a package while enjoying the beauty of various destinations worldwide.

- Luxury fever - the consumption of luxury products and services has been growing rapidly in the past decades. According to some studies, the consumption of luxury products has grown four times more than the consumption of all other products (Kovač-Žnideršić \& Marić, 2007, p. 212).

Unlike consumers in developed countries, who expect corporate marketing communication to provide information on the specifics features and differences between brands, consumers in transition countries primarily expect information about products themselves. The problem of companies in transition economies can also be the negative experience from transition countries with "Western consumerism," which is the consequence of economic changes, political changes, and demographic changes, in the 
sense of an increase in the number of inhabitants and a growing gap between the needs and the possibility to meet them. Many consumers regard the invasion of imported products on their markets as "cultural imperialism" - imposition of foreign/Western values and lifestyle through hyperactive and powerful advertising (Kovač-Žnideršić \& Marić, 2007, p.214).

A common characteristic of contemporary consumer behavior patterns, both for developed and developing countries, is the intensification of word-of-mouth communication between consumers themselves, establishing and strengthening relationships between them, and further mitigating the efficiency and effectiveness of traditional marketing communication between companies and the market. Predominance of word-of-mouth communication between consumers as compared to traditional messages sent from companies to the market is the consequence of resistance by consumers to corporate marketing appeals. According to some studies, modern-day consumers are oversaturated by the amount of information served by companies, with the number of commercial messages and appeals ranging from about 3000 messages (McConnel \& Huba, 2003, p. 6) up to as many as 6000 per day (Meiners, Schwarting, \& Seeberger, 2010, p. 81). Word-of-mouth communication is defined as messages and information on the company, its credibility, trust in, business practices, offer and quality of its products and services, exchanged in the communication between individual consumers (Gronroos, 2004, p. 269).

A great attention of the academic and business communities was drawn by the report on the future of marketing published by Economist Intelligence Unit (2006). The research included 200 CEOs and marketing department executives in companies worldwide, and the conclusion was very clear: companies and their executives are extremely dissatisfied with their capabilities and ability to measure specifically the results of their conducted marketing campaigns, i.e. to establish the return on their marketing investment, whether online or offline. A need was stated for introducing new business control analysis, such as return on objectives (ROO) and return on marketing investment (ROMI). The research found that new consumer behavior patterns are the cause of the above, and these patterns are manifested through consumers' active search for information using modern interactive information technologies. Consumers are better networked, have a better interpersonal communication, are better organized, and they approach the issue of purchase decision with much more caution and expertise.

The research leads to the conclusion that it is a real challenge for marketers in companies to use their system of integrated marketing communication and stimulate a specific form of consumer response, which must be monitored, measured and analyzed. Some of the most significant elements of consumers' response to companies' marketing activities are positive decisions to buy products and services of the observed companies, and subsequent positive word-of-mouth communication, whereby the existing consumers attract new consumers to the company.

Research into and thinking about the phenomenon of contemporary consumers and their role in the system of social and economic relation that attracted great interest of academic and business communities was published by Gabriel \& Lang (2006), who gave a very detailed presentation of understanding the concepts of consumer and consumption over historical periods, and pose many significant questions before the economic, and especially marketing science and practice. The authors point to changes in the very understanding of the notion of consumerism, viewing it as a part of different intellectual traditions, thus adding it different meanings (Gabriel \& Lang, 2006, p. 8):

- Consumerism as a moral doctrine in developed countries - consumption negates the puritan ethical negation of the individual's self and needs, establishing itself as the essence of quality of life, and through freedom of choice, purchase and use of goods and services, and customer delight, consumerism becomes the driving force for achieving freedom, power and happiness; 
- Consumerism as an ideology of conspicuous consumption - consumption and enjoyable life become substitutes for religion, and determine the way of work and political events as mechanisms through which social relationships and status differences are established;

- Consumerism as the economic ideology of global development - the key factor of international social and economic relations, development of individual countries and regions worldwide, emergence and functioning of global and transnational companies;

- Consumerism as a political ideology - influences understanding the role of the state in a different way, i.e. this role implies much more creation of markets, ambience, rules, and control of their application, than earlier passive role of providing public goods and services. Consumer rights obtain a political dimension and become basic human rights in almost all social systems and communities;

- Consumerism as a social movement seeking, protecting and promoting consumer rights - over the past two centuries, the focus of activities has moved from the best proportion of price, value and quality of products and services to care for environment and scarce resources.

It is beyond a doubt that consumerism and consumers are in for dramatic changes and uncertainty in the future, as a consequence of powerful and hardly predictable action of technological, economic, demographic, environmental, and many other changes. A big question mark can be placed before the future full freedom of consumer choice, in the sense that choice will exist, but consumers will not be aware of all the consequences of their choice, nor will they be willing to accept the responsibility for them. This freedom of consumer choice will most probably be limited to an extent, both in range and in type of choice, and consumerism will be increasingly influenced and shaped by factors, such as political ideology, production, international trade and economic relations, economic theory, cultural and moral values, class relationships, etc.

There is a growing number of marketing theoreticians, but also business leaders, advocating a holistic and multidimensional view of the consumer, who is not merely a buyer and user of products and services offered by companies on the market, but a networked member of a large number of social groups, connected by various forms of links and relations, sharing the feature that, for the company, they function as stakeholder groups (Daub \& Ergenziger, 2005, p. 1006).

Appreciating the identified and anticipated changes, Gabriel \& Lang (2006) promote in their study a new consumer - contemporary and particularly active on the market and in society, implying the following roles:

- Consumer as someone choosing between different alternatives - this role is very often manipulated in the sense that relevant and irrelevant are not distinguished, so that the consumer is placed in a position to invest the same level of engagement in choosing relevant things, e.g. choice of employer or partner/spouse, and in choosing less relevant things, e.g. an order in the restaurant.

- Consumer as a communicator - represents one of the most important, and, at the same time, most obvious decisions of the consumer to communicate. Use, disposal, and ownership of goods and services send a very clear message about the personal traits of individual consumers, about their status, social role, and lifestyle. Functioning of the entire socioeconomic systems is based on the transfer of meaning and communication that consumption implies. Marketing as a science and practice has either negated this role of the consumer or neglected its most important part - the consumer is neither a passive recipient of the message sent by a company, nor is he or she merely somebody who responds to the company's message; rather, a consumer is an active transmitter of messages to other consumers by means 
of word-of-mouth communication, where he or she can also modify or create an entirely new message compared to the one sent by the company. This role gives consumers on the market a great power to define the company's destiny, and consumers are becoming increasingly aware of this role.

- Consumer as a researcher - this role was mostly viewed narrowly in economic and marketing practice, through the prism of information gathering aimed at making the best decision in the sense of "money for value of choice." The consumer's curiosity, as the main human characteristic, as well as the behavior motive and determinant, was almost left unmentioned, let alone researched. Contemporary consumers want to fulfil all of their potential, and if they notice that another consumer has forgotten, they will remind him that any consumer has no right not to be happy. Curiosity makes the consumer an active participant on the market, who gathers, researches, analyses, and detects information, which he subsequently shares with other consumers;

- Consumer as a seeker after their own identity - enables establishing similarities and differences between different consumers, and, in essence, implies an analysis of psychological determinants of consumer behavior. It is important to point out that quest for identity is not limited to a single individual, but also to other consumers who seek to know the identities of other consumers, thus intensifying interrelations between consumers on the market on which companies have no influence;

- Consumer as a hedonist and/or artist - attitude to and understanding of consuming art and hedonism differs from one society to another, but the common trait is that hedonism does not only include physical enjoyment, but, much more, an emotional experience. This role of the contemporary consumer results in something that is defined in marketing as a feeling of satisfaction with purchased and used product and service, where this very satisfaction is the primary goal, ideal, focus of all company's marketing activities. In the recent years, a trait in thinking is emerging according to which consumers in general are not satisfied, but they do not know the reason for it. These reasons, apparently, lay in the fact that consumers seek to achieve satisfaction by getting more of something that they already have, and the problem is that what we already have does not satisfy us - either to the extent that we would want, or in the long run. The feeling of consumer satisfaction affects not only economic but also all other spheres of functioning of a society;

- Consumer as a victim - the idea of the consumer as an unprotected market participant, who is easy to deceive, manipulate, blackmail, etc. is being abandoned to an increasing extent, as consumerism and consumer organizations have greatly reduced it. However, the consumer can, nowadays, appear in a role which used to be reserved solely for companies and the state, that is, the role of the one who can victimize others; that is, the consumer still often has the role of victim, but the culprits are no longer companies and the state, but rather other consumers. Motives of word-of-mouth communication, making a strong impact on the behavior of other consumers, do not always have to be of ethical and human nature;

- The consumer as a rebel - refers to the role, which is a consequence of a feeling of dissatisfaction with the current state and the desire to make this known. This role and feeling may be so strong as to create entirely new patterns of consumer behavior, taking on elements of popular culture. The consumption of cigarettes by women is deemed to be a reflection of their solidarity and rebellion against the predominantly male portion of society that women who consume cigarettes with lipstick are women of easy virtue. The phenomenon of jeans as a 
fashion item and its rise to the level of status symbol is another example of consumer rebellion;

- Consumer as an activist - represents one of the essential roles of the contemporary consumer, which best reflects all the changes that the consumer as a market participant has undergone through the evolution of consumerism. This consumer role is manifested from changed demands to companies and the state to specific organized actions aimed at meeting those demands. Consumer boycott - reduction or withdrawal from purchasing specific items and services provided by specific producers from specific industries and states, and positive purchases - increase or recommendation of some other products, services, produces, industries and countries - are a powerful tool in the hands of consumer activists, characterized by organization, desire to change, awareness of undertaking specific actions, collectivism, values, and consequences. The main instrument of realisation of the role of consumers as activists, a role characterizing modern society and market, is word-of-mouth communication:

- Consumer as a citizen - implies a role that has both positive and negative implications for the consumer. One of the first and basic consumer rights, and consequently roles, pertains to the right to choose. However, the role of citizen imposes on the consumer certain rules such as common interest, higher cause, responsibility and respecting the will of minority, although it is often contrary to his own needs and desires. The role of citizen influences and shapes the role of the one who has the right of freedom of choice which is predominantly led by individual interests and motives. The citizen consumer is equal with the others, whereas a consumer with the right of choice is unique and expects to be treated so.

Nisbet \& Kotcher (2009) studied the engagement and impact of specific consumers - opinion leaders in situations that have a broader social significance, and emphasize that resolving this type of problems, for instance climate changes, is impossible without active participation of these consumers. Opinion leaders are specific individuals serving within social groups as information transmitters by direct word-of-mouth communication, whereby they significantly shape public opinion. The strong influence of opinion leaders is not determined by some kind of formal rank or position in society, but by their knowledge, connections with other consumers, and their personal characteristics. Opinion leaders do not merely draw attention to themselves, but rather feature as models of how other consumers should react and behave.

The modern-day consumer undoubtedly features as an ever-present element of any analysis of events in a social system, and needs to be understood as the most active participant on the market, where his activity level can be monitored through the intensity of word-of-mouth communication.

\section{Conclusion}

Modern-day consumers seek on a daily basis to redefine the sense of their own and human advancement in general, to contribute to raising the quality of life, and to reach a level of satisfaction with life and work. Consumers constantly redefine cultural patterns of living by changing their articulated preferences and desires, and consequently, changing the type and style of consumption.

Despite the identification of a large number of trends in consumer behavior, new patterns of their activity in society, the modern consumer remains a great, unpredictable and ever-changing enigma for the company. Demographic changes and environmental problems of depletion of scarce resources and environmental impact represent factors which will, in the future, influence consumers who will, on the other hand, through their undertaken various roles, continue even more intensively, through interpersonal communication, to create economy and society in which they exist. 
The very concept of marketing has become a sense unto itself and lost its own value - being in the service of consumers. Loss of consumer confidence in companies' marketing activities has resulted in consumers turning to one another and networking, creating consumer media, which are under their full control. The key process on the market, which determines the fate of the company, occurs completely beyond its control.

Marketing as a science and practice must become a complex and fluid system of networked relations which constantly redefines itself towards integration with the changes in post-modern consumers and their modus vivendi. The key challenge of companies in the future will be to provide authenticity, transparency, sincerity and credibility in dialogue with consumers, and acceptance of communication processes between consumers as a general rule of business activities.

\section{References}

Andrusia, D., \& Haskins, R. (2000). Brand Yourself: How to Create an Identity for a Brilliant Career. New York: Ballantine Books.

Arnould, J. E., Price, L. L., \& Zinkhan, M. G. (2004). Consumers. McGraw-Hill.

Brinkmann, J., \& Peattie, K. (2008). Consumers Ethics Research: Reframing the Debate about Consumption for Good. Electronic Journal of Business Ethics and Organization Studies, 13(1), 22-31.

Daub, C. H., \& Ergenziger, R. (2005). Enabling Sustainable Management through a New Multidisciplinary Concept of Customer Satisfaction. European Journal of Marketing, 39(9/10), 998-1012.

Economist Intelligence Unit (2006). The Future of Marketing - from Monologue to Dialogue. The Economist.

Flavin, C. (2004). State of the World 2004: A Worldwatch Institute Report on Progress toward a Sustainable Society (Preface). New York: W. W. Norton \& Co., Inc.

Firat, A. F., \& Dholakia, N. (2006) Theoretical and Philosophical Implications of Postmodern Debates: Some Challenges to Modern Marketing. Marketing Theory, 6, 123-161.

Gabriel, Y., \& Lang, T. (2006). The Unmanageable Consumer. SAGE Publication

Gronroos, Ch. (2004). Service Management and Marketing. John Wiley \& Sons.

Kotler, P., \& Keller, K. L., (2006). Market Management (14th ed.). Prentice Hall.

Kovač-Žnideršić, R., \& Marić, D. (2007). Društvene determinante ponašanja potrošača [Social determinants of consumer behavior]. Ekonomski fakultet Subotica.

McConnell, B., \& Huba, J. (2003). Creating Customer Evangelists. Dearborn Trade Publishing.

Meiners, N. H., Schwarting, U., \& Seeberger, B. (2010). The Renaissance of Word of Mouth Marketing: A New Standard in 21st Century Marketing Management. International Journal of Economics Science and Applied Research, 3(2), 79-97.

Nisbet, M. C., \& Kotcher, J. E. (2009). A Two Step Flow of Influence? Opinion Leader Campaigns on Climate Changes. Science Communication, 30(3), 328-354.

Urban G., (2005). Don't Just Relate - Advocate!: A Blueprint for Profit in the Era of Customer Power. Prentice Hall. 